\title{
SEASONAL CHANGES IN NITROGEN, PHOSPHORUS, BOD AND COD REMOVAL IN BYSTRE WASTEWATER TREATMENT PLANT
}

\author{
Iwona Skoczko', Joanna Struk-Sokołowska', Piotr Ofman ${ }^{1}$ \\ 1 Bialystok University of Technology, Department of Technology in Environmental Engineering and Protection, \\ Wiejska 45E Str., 15-351 Białystok, Poland, e-mail:p.ofman@pb.edu.pl
}

Received: 2017.05.19

Accepted: 2017.06.01

Published: 2017.07.01

\begin{abstract}
The aim of this study was to determinate seasonal changes in industrial wastewater treatment effectiveness. Studies were carried out in mechanical-biological wastewater treatment plant in Bystre near Giżycko to which inflows mixture of domestic and dairy wastewater. Laboratory studies were carried out by Water and Wastewater Company in Giżycko. For statistical analysis results form years 2014 and 2015 were considered. The scope of statistical analysis includes basic statistical measures including arithmetic mean, median, minimum, maximum and standard deviation. Changes in seasonal treatment effectiveness were shown by Fisher-Snedecore LSD test. Seasonal changes were observed for BOD, COD and total nitrogen removal effectiveness. Total phosphorus was not subjected to that kind of changes.
\end{abstract}

Keywords: wastewater treatment, seasonal changes, dairy wastewater

\section{INTRODUCTION}

Despite the measurable environmental benefits and relatively low cost of wastewater treatment, biological methods are not devoid of operational problems [Żaba et al. 2011]. One of them is the wastewater temperature in winter and early spring [Bugajski et al. 2015]. Temperature fluctuations of wastewater entering the treatment plant during the aforementioned period are caused by the flow of melted water or wastewater cooling in open sand traps, settling tanks and bioreactors [Brzezińska, Zawilska 2010]. Additionally, it has been determined that effluent temperature fall may occur during its flow through gravitational channels [Brzezińska 2011]. Poland geographic location determines atmospheric air annual average temperature at about $8{ }^{\circ} \mathrm{C}$. This results in a drop of wastewater temperature in open biological reactors to about $12{ }^{\circ} \mathrm{C}$ between November and April. Under Polish legislation it has been determined that the nitrification process is less efficient at less than $12{ }^{\circ} \mathrm{C}$, and in that case, the amount of nitrogen excreted in purified effluent is not taken into account in facility performance assessment
[Bugajski 2011]. It is assumed that wastewater temperature at which treatment processes are most effective is about $20^{\circ} \mathrm{C}$ [Rabajczyk, Garbala 2011], but with its decrease the biological treatment efficiency is clearly decreasing [Brzezińska 2011]. This results in a wastewater chemical quality deterioration and consequently in deterioration of receiver state [Wałęga et al. 2010].

The aim of the study was to determine occurrence of seasonal changes in treatment efficiency of municipal and dairy mixture effluents entering the wastewater treatment plant in Bystre near Giżycko.

\section{MATERIALS AND METHODS}

The mechanical-biological wastewater treatment plant in Bystre near Giżycko was commissioned in 1995 . Facility was modernized in the years 2002-2003. Treatment plant maximum daily capacity is $14,000 \mathrm{~m}^{3} \cdot \mathrm{d}^{-1}$, while daily average amount of wastewater is $6400 \mathrm{~m}^{3} \cdot \mathrm{d}^{-1}$. Objects equivalent population (PE) is 98615 . Municipal wastewater treatment plant receives dairy waste 
from the District Dairy Cooperative in Giżycko. Liquid waste is brought to sewage storage point in amount of about $9000 \mathrm{~m}^{3} \cdot$ year $^{-1}$.

Raw sewage flows into the wastewater treatment plant by gravity and pressure sewage system. Preliminary mechanical wastewater treatment (Fig. 1) is performed in grids building. Screenings accumulating on the grid are automatically sent to screw feeder, drained in hydraulic press and transported to the container. The next purification step is a mechanical sand separator, where in result of a slowed wastewater flow occurs precipitation and sedimentation of mineral suspension. In addition, sand separator is aerated with compressed air to improve flotation of floating parts. Collected sand pulp, contaminated with organic compounds, is transported to the separator and sand scrubber. Rinsed and dewatered sand is directed to a container, and the effluents for further biological treatment.

After mechanical part, wastewater flows to biological chambers, which are the basic element of biological treatment. In a first step the wastewater flows into phosphorus removal chamber (anaerobic), then to the denitrification chamber (anoxic), to which nitrates stream is recycled from nitrification chamber (internal recirculation). Wastewater from the denitrification flows to nitrification chambers (aerobic). In denitrification and nitrification chambers occurs biological treatment based on the life processes of microorganisms present in activated sludge. After treatment in bioreactors mixture of sludge and sewage flows through transfers chamber section to two secondary settling tanks, where separation of activated sludge and treated wastewater is being performed. Sludge gathered at the bottom of settling tank is scraped into the sedimentary hopper and transported to excessive sludge recirculation pumping station. There it is pressed to the beginning of biological treatment (external recirculation) or as excess sludge is discharged to the gravity thickening. Technological scheme of studied wastewater treatment plant is shown at figure 1 [www.pwikgizycko.pl].

Analytical study results were provided by Water and Sewerage Company in Giżycko city were used. The studys were conducted in years

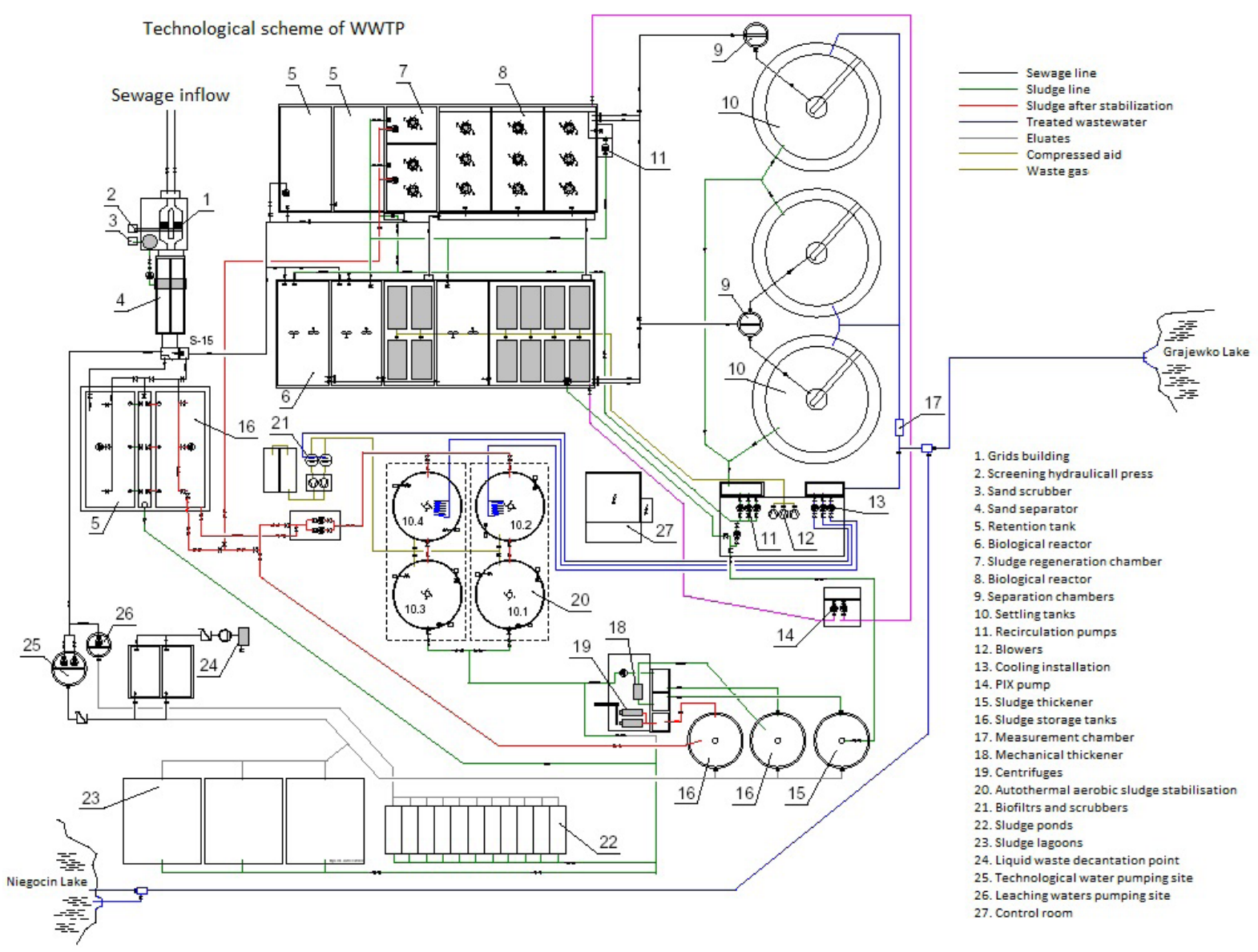

Figure 1. Technological scheme of wastewater treatment plant [www.pwikgizycko.pl] 
2014 and 2015. Analysis of raw and treated sewage composition was conducted 4 times each month - every 7 days. Analyses included following parameters: BOD, COD, total nitrogen and total phosphorus. Studied wastewater treatment plant was characterized by PE at level of 98615. Analysis were performed according to the standards:

- BOD- PN-EN 1899-1:2002

- COD- PN- ISO 6060:2006

- Total nitrogen- PB-13/2006/PG wyd. 3 z 02.012013

- Total phosphorus- PN-EN ISO 6878:2006+Ap1. 2010+Ap2.:2010 p.7

The scope of statistical analyzes included the determination of basic statistics such as arithmetic mean, median, minimum, maximum, and standard deviation. Determination of seasonal occurrence was made based on the LSD FischerSnedecor test results. The Fischer LSD test was chosen because of its strength and the fact that it is used for checking the results of other LSD tests [12]. However, to perform the Fisher LSD test, the variable must meet two conditions. The first is the distribution normality, while the second is variance homogeneity. For this purpose, variables distribution, accepted for further analyzes was checked using the Kolomogorov-Smirnov, Lilliefors and Shapiro-Wilk tests. It was assumed that the variable was characterized by normal distribution if at least one of the above tests yielded a probability of less than 0.05 . Another tested condition was accepted for analysis variables variance homogeneity. This property of the variables was checked using the Hartley, Cochran and Bartlett tests.

Statistical analysis included a total of 624 results of the removal of the parameters, with 156 results for each of tested parameter. Efficiency of removal was determined by the following equation:

$$
\eta=\frac{C_{s}-C_{o}}{C_{s}} \cdot 100 \%
$$

where: $\eta$-removal efficiency expressed in $\%$
$C_{S}$ - concentration or value of the indicator in raw wastewater expressed in $\mathrm{mg} \cdot \mathrm{dm}^{-3}$

$C_{O}$ - concentration or value of the indicator in treated wastewater expressed in $\mathrm{mg} \cdot \mathrm{dm}^{-3}$

The beginning and end of a given season were determined based on calendar dates, it was assumed that spring begins on 21 March, summer 22 June, autumn 23 September, and winter 22 December. All statistical analyzes were performed using Statistica 12.5 licensed software in the Polish language version running on the Windows 10 platform.

\section{RESULTS AND DISSCUSION}

Table 1 presents basic statistics for the removal efficiency of individual parameters in 2014-2015. Arithmetic mean and median values for studied indicators had similar values. Removal efficiency of individual parameters varied from 97.86 to $99.75 \%$ for BOD, 85.75 to $98.02 \%$ for COD, 70.91 to $97.13 \%$ for total nitrogen and 85.56 to $98.21 \%$ for total phosphorus. The highest deviation was observed for total nitrogen, which was $3.22 \%$ and the lowest for BOD removal $(0.29 \%)$. The standard deviation of COD and total phosphorus were equal to 1.81 and $1.56 \%$, respectively. Based on the obtained descriptive statistics values, it was found that the removal effects calculated for individual parameters did not show any significant differences during the year.

Table 2 summarizes the basic statistical measures at different times of year. The average removal effects of the studied parameters were very high and remained at the level of more than $90 \%$ irrespective of the time of year. Individual parameters median values were close to their arithmetic mean throughout the year irrespective to season, suggesting a small difference in treatment effect over study period. Confirmation of large changes absence in efficiency of wastewater treatment plant over considered period under (years 2014

Table 1. Basic statistics of wastewater treatment effectiveness in 2014 and 2015

\begin{tabular}{|c|c|c|c|c|c|}
\hline Variable & Arithmetic mean [\%] & Median [\%] & $\operatorname{Min}[\%]$ & $\operatorname{Max}[\%]$ & SD [\%] \\
\hline$\eta \mathrm{BOD}$ & 99.25 & 99.28 & 97.86 & 99.75 & 0.29 \\
\hline$\eta \mathrm{COD}$ & 94.73 & 94.96 & 85.75 & 98.02 & 1.81 \\
\hline$\eta$ Total $\mathrm{N}$ & 91.89 & 92.36 & 70.91 & 97.13 & 3.22 \\
\hline$\eta$ Total P & 96.16 & 96.44 & 85.56 & 98.21 & 1.56 \\
\hline
\end{tabular}


Table 2. Basic statistics of wastewater treatment effectiveness in different year season

\begin{tabular}{|c|c|c|c|c|c|c|}
\hline Variable & $\begin{array}{l}\text { Year } \\
\text { season }\end{array}$ & $\begin{array}{c}\text { Arithmetic mean } \\
{[\%]}\end{array}$ & Median [\%] & $\operatorname{Min}[\%]$ & Max [\%] & SD [\%] \\
\hline$\eta \mathrm{BOD}$ & \multirow{4}{*}{ Winter } & 99.00 & 99.02 & 97.86 & 99.58 & 0.33 \\
\hline$\eta \mathrm{COD}$ & & 93.44 & 94.27 & 85.75 & 97.27 & 2.14 \\
\hline$\eta$ Total N & & 90.81 & 91.41 & 81.00 & 94.81 & 3.40 \\
\hline n Total P & & 95.95 & 96.17 & 86.90 & 97.64 & 1.75 \\
\hline$\eta \mathrm{BOD}$ & \multirow{4}{*}{ Spring } & 99.26 & 99.30 & 98.55 & 99.73 & 0.21 \\
\hline$\eta \mathrm{COD}$ & & 95.22 & 95.18 & 91.97 & 98.02 & 1.22 \\
\hline$\eta$ Total N & & 91.34 & 91.59 & 70.91 & 94.88 & 3.86 \\
\hline$\eta$ Total P & & 96.32 & 96.44 & 93.69 & 98.21 & 1.06 \\
\hline$\eta \mathrm{BOD}$ & \multirow{4}{*}{ Summer } & 99.38 & 99.43 & 98.75 & 99.75 & 0.21 \\
\hline$\eta \mathrm{COD}$ & & 95.35 & 95.69 & 87.31 & 97.74 & 1.89 \\
\hline$\eta$ Total N & & 93.70 & 93.49 & 88.94 & 97.13 & 2.05 \\
\hline$\eta$ Total P & & 96.10 & 96.55 & 85.56 & 98.19 & 2.02 \\
\hline$\eta \mathrm{BOD}$ & \multirow{4}{*}{ Autumn } & 99.34 & 99.38 & 98.86 & 99.69 & 0.23 \\
\hline$\eta \mathrm{COD}$ & & 94.87 & 94.93 & 92.19 & 96.92 & 1.22 \\
\hline$\eta$ Total N & & 91.69 & 92.03 & 85.38 & 95.84 & 2.60 \\
\hline$\eta$ Total P & & 96.28 & 96.77 & 90.94 & 97.66 & 1.28 \\
\hline
\end{tabular}

and 2015) are small standard deviation values and relatively small range of parameters variation.

Although the average removal effects of individual parameters remained high, there observed were some differences in wastewater treatment plant operation over the seasons. The average BOD removal effect increased after season changed from winter to summer. This parameter removing effect was $99.00 \%$ in winter, $99.26 \%$ in spring and $99.38 \%$ in summer. In autumn, a slight decrease in efficiency value was observed (99.34\%). A similar relationship has been observed for COD. During the winter, the removal efficiency was the smallest and equaled $93.44 \%$. Then, during the spring and summer, a better removal of this parameter was observed, which equaled $95.22 \%$ and $95.35 \%$ respectively. On the other hand, in the autumn a slight deterioration in purification effect of this parameter was observed, which equaled then $94.87 \%$. The most observable change in removal efficiency between individual seasons was observed with the example of total nitrogen. For this parameter, the removal rate increased from $90.81 \%$ in winter and $91.34 \%$ in spring to the maximum value observed in summer $(93.70 \%)$. At the same time, as in case of other parameters, the total nitrogen removal efficiency decreased to $91.69 \%$ in autumn. The last from analyzed parameters (total phosphorus) did not show clearly observed seasonal changes in removal efficiency over research period. In winter, the total phosphorus was removed with an efficiency of $95.95 \%$, in spring $96.32 \%$.
In summer time again, a decrease in the removal efficiency of this parameter was observed to a value of $96.10 \%$ and a slight increase in autumn to $96.28 \%$. The discussed changes in wastewater treatment plant efficiency year seasons were presented in Figure 2.

Similar effects of BOD and COD removal were presented by Dąbrowski [2011] in a paper devoted to the analysis of dairy effluents treatment efficiency from the Mlekovita dairy cooperative in Wysokie Mazowiecki. Dąbrowski's BOD removal efficiency was $99 \%$, while the COD removal efficiency was $98 \%$. Dąbrowski observed slightly better effect of total phosphorus removal $(97 \%)$ comparing to studied treatment plant. Bartkowska et al. [2011], while conducting research on the Hajnówka wastewater treatment plant effectiveness, which purifies the mixture of municipal and dairy effluents, obtained similar results. Authors observed BOD and COD removal at $98.87 \%$ and $95.58 \%$, respectively. Total nitrogen was removed slightly worse in comparison to studied treatment plant and its removal efficiency in Hajnówka was $91.54 \%$, while the total phosphorus was removed with similar efficiency, which was $96.37 \%$ for the Hajnowka plant. Average removal effects obtained by Bartkowska and Klaus [2013] in wastewater treatment plants in Olecko were slightly lower than those observed in Bystre. BOD and COD were removed with efficiencies of 98.90 and $96.39 \%$, respectively. On the other hand, the reduction of nitrogen and total phosphorus was 92.58 and $95.51 \%$ 


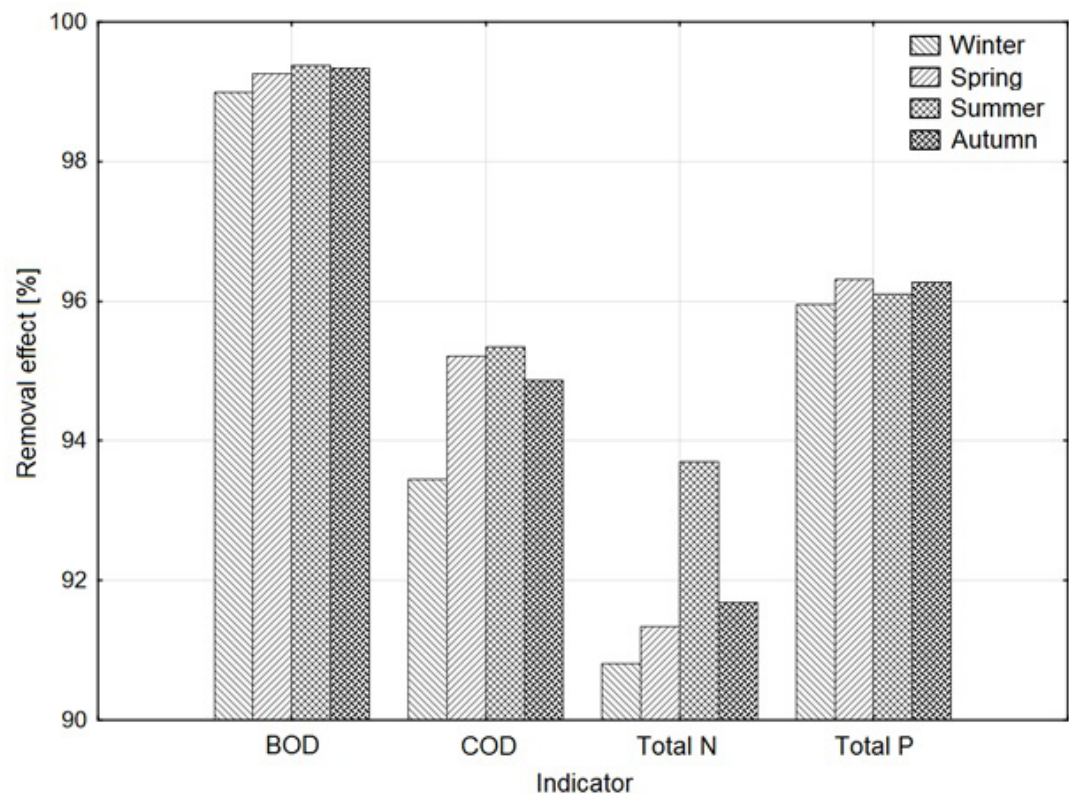

Figure 2. Average wastewater treatment effectiveness per year seasons

According to data presented in Table 3, the Lilliefors and Shapiro-Wilk tests showed that all variables had a normal distribution because resulting probability (p) was less than 0.05 . This means that the empirical distribution was more than $95 \%$ consistent with the Gaussian theoretical distribution. On the other hand, according to the Kolomogorov-Smirnov test, only BOD removal efficiency did not show normal distribution due to the probability value greater than 0.05 obtained for this variable. Hartley, Cochran and Bartlett tests (Table 4) have shown that all variables in dataset have uniformity in variance. This is evidenced by the probability result (p), which is less than or equal to 0.01 for all conducted tests. This means that variables accepted for analysis have a similar structure with a probability greater or equal to $99 \%$.

Tables from 5 to 8 show the Fisher-Snedecor NIR test results for presence of statistically significant differences in removal effectiveness of studied parameters between individual seasons. Table 5 lists the NIR values for BOD. The test results confirmed in a statistical manner the changes occurring in the BOD removal effectiveness during the year, as shown in Figure 2. There were statistically significant differences between the winter and the rest of the year (spring, summer, autumn). This difference refers to the smallest value of removing effect of this parameter during winter season and its gradual improvement over the rest of year. Another difference occurred be-

Table 3. Normal variables distribution

\begin{tabular}{|c|c|c|c|c|}
\hline \multirow{2}{*}{ Variable } & \multirow{2}{*}{ Kołomogorow-Smirnows Test } & \multirow{2}{*}{ Lillieforss Test } & \multicolumn{2}{|c|}{ Shapiro-Wilks Test } \\
\cline { 3 - 5 } & & $\mathrm{p}<0.05$ & 0.91 & 0.00 \\
\hline$\eta$ BOD & $p>0.20$ & $p<0.01$ & 0.89 & 0.00 \\
\hline$\eta$ COD & $p<0.01$ & $p<0.01$ & 0.83 & 0.00 \\
\hline$\eta$ Total N & $p<0.01$ & $p<0.01$ & 0.71 & 0.00 \\
\hline$\eta$ Total P & $p<0.01$ & & & \\
\hline
\end{tabular}

Table 4. Variation homogeneity of studied variables according to year season

\begin{tabular}{|c|c|c|c|c|c|}
\hline Variable & Hartleys Test & Cochrans Test & Bartletts Test & a & $\mathrm{p}$ \\
\hline$\eta \mathrm{BOD}$ & 2.53 & 0.44 & 11.81 & 3 & 0.01 \\
\hline$\eta \mathrm{COD}$ & 3.10 & 0.41 & 18.99 & 3 & 0.00 \\
\hline$\eta$ Total $\mathrm{N}$ & 3.54 & 0.40 & 16.86 & 3 & 0.00 \\
\hline$\eta$ Total P & 3.66 & 0.41 & 18.71 & 3 & 0.00 \\
\hline
\end{tabular}


Table 5. Fishers LSD test results for BOD removal

\begin{tabular}{|c|c|c|c|c|}
\hline $\begin{array}{c}\text { Year } \\
\text { season }\end{array}$ & Winter & Spring & Summer & Autumn \\
\hline Winter & & 0.00 & 0.00 & 0.00 \\
\hline Spring & 0.00 & & 0.04 & 0.18 \\
\hline Summer & 0.00 & 0.04 & & 0.46 \\
\hline Autumn & 0.00 & 0.18 & 0.46 & \\
\hline
\end{tabular}

Table 7. Fishers LSD test results for total nitrogen removal

\begin{tabular}{|c|c|c|c|c|}
\hline $\begin{array}{c}\text { Year } \\
\text { season }\end{array}$ & Winter & Spring & Summer & Autumn \\
\hline Winter & & 0.45 & 0.00 & 0.20 \\
\hline Spring & 0.45 & & 0.00 & 0.61 \\
\hline Summer & 0.00 & 0.00 & & 0.00 \\
\hline Autumn & 0.20 & 0.61 & 0.00 & \\
\hline
\end{tabular}

tween spring and winter, spring and summer. The next observed difference occurred between summer and winter and autumn. The last statistically significant difference occurred between winter and autumn. The result of Fisher-Snedecor test confirms the dependence of BOD removal depending on the time of the year, which indirectly results from Figure 2.

In the case of COD (table 6) statistically significant differences were observed between winter and the rest of the year. There were no statistically significant differences observed between spring, summer and autumn seasons. The result of NIR test suggests that temperature differences between spring and autumn do not significantly affect COD removal efficiency, while the lower temperatures in winter will lower this parameter removing effect. Confirmation of obtained dependence from Fisher's NIR test, is a large difference in mean COD removal in winter compared to the rest of the year.

According to Fisher-Snedecor NIR test, changes observed in total nitrogen removal efficiency (Table 7) occurring during study period show a statistically significant difference only between summer and the rest of the year. Improvement in removal efficiency of this parameter is directly related to temperature increase of wastewater flowing to facility. Statistical analysis results are consistent with total nitrogen average removal efficiency shown in Figure 2, which is the largest in summer. In the case of total phosphorus (Table 8), there were no statistically significant differences in the removal efficiency of this parameter observed.
Table 6. Fishers LSD test results for COD removal

\begin{tabular}{|c|c|c|c|c|}
\hline $\begin{array}{c}\text { Year } \\
\text { season }\end{array}$ & Winter & Spring & Summer & Autumn \\
\hline Winter & & 0.00 & 0.00 & 0.00 \\
\hline Spring & 0.00 & & 0.72 & 0.35 \\
\hline Summer & 0.00 & 0.72 & & 0.20 \\
\hline Autumn & 0.00 & 0.35 & 0.20 & \\
\hline
\end{tabular}

Table 8. Fishers LSD test results for total phosphorus removal

\begin{tabular}{|c|c|c|c|c|}
\hline $\begin{array}{c}\text { Year } \\
\text { season }\end{array}$ & Winter & Spring & Summer & Autumn \\
\hline Winter & & 0.31 & 0.67 & 0.36 \\
\hline Spring & 0.31 & & 0.55 & 0.91 \\
\hline Summer & 0.67 & 0.55 & & 0.62 \\
\hline Autumn & 0.36 & 0.91 & 0.62 & \\
\hline
\end{tabular}

It should be noted that research into seasonal changes in effluent treatment efficiency is rarely reported in the literature. Most of the work is devoted exclusively to analysis of removal efficiency of individual parameters from wastewater, without considering the changes that occur in year seasons.

\section{CONCLUSIONS}

1. Seasonal changes in BOD removal efficiency were observed. The removing efficiency of this parameter increased from winter to summer

2. The compounds described by COD parameter were the least removed during winter. For rest of the year this parameter removing effect was similar.

3. Total nitrogen was most effectively removed during summer. Total nitrogen removing effectiveness for remaining part of year did not exceed $92 \%$.

4. Total phosphorus did not show seasonal variations during research period. Removing effect of this parameter was about $96 \%$ regardless of year season.

5. Removal effect for studied wastewater parameters was high and remained above $90 \%$ during entire research period.

\section{Acknowledgments}

The authors would like to thank the Enterprise of Water Supply and Sewerage in Gizycko for providing data on the quality param- 
eters of the wastewater in the sewage treatment plant in Bystych.

The study was conducted as a research project S/WBiIS/3/2014 in Faculty of Building and Environmental Engineering of BUT and financed by Ministry of Science and Higher Education.

\section{REFERENCES}

1. Bartkowska I., Dzieni L., Wawrentowicz D., 2011. Efficiency of sewage treatment plant in Hajnówka and proposal of its modernization, Journal of Ecological Engineering, no. 24, 226-235 (in Polish).

2. Bartkowska I., Klaus W., 2013. Performance analysis of sewage treatment plant working in the SBR system, Economics and Environment, no. 4(47), 107-117 (in Polish).

3. Brzezińska A., Zawilski M., 2010. Dynamic modeling of the biological treatment process for combined wastewater: A case study, Environmental Protection, no. 3, 21-26 (in Polish).

4. Brzezińska A., 2011. Variability of combined wastewater temperature on the basis of on-line measurements, Journal of Ecological Engineering, no. 26, 290-302 (in Polish).

5. Bugajski P., Kaczor G., Bergel T., 2015. The removal of reliability nitrogen in wastewater treatment plant witch sequencing biological reactor, Acta Scientiarum Polonorum, no. 14(3), 19-27 (in Polish).

6. Bugajski P., 2011. The effect of sewage temperature on values of the selected sewage pollution indexes for the sequential batch reactor (SBR) treatment plant, Infrastructure and Ecology of Rural
Areas, no. 2, 7-15 (in Polish).

7. Dąbrowski W., 2011. Determination of pollutants concentration changes during dairy wastewater treatment in Mlekovita Wysokie Mazowieckie, Journal of Ecological Engineering, no. 24, 236-242 (in Polish).

8. Drzewicki A., 2004. Bioindication significance of microfauna in sewage treatment by activated sludge method, Gas, Water and Sanitary Engineering, no. 10, 359-361. (in Polish)

9. http://www.pwikgizycko.pl/oczyszczalnia.html

10. Kaczor G., 2008. The effect of sewage temperature on values of the selected sewage pollution indexes for the sequential batch reactor (SBR) treatment plant, Infrastructure and Ecology of Rural Areas, no. 3, 129-137 (in Polish).

11. Rabajczyk A., Garbala A., 2011. Role of active sludge in the reduction of inorganic pollutants on the example of the sewage treatment plant in Suchedniow, Journal of Swietokrzyskie Mountains Region Rocznik Świętokrzyski series B- Natural Sciences, no. 32, 97-112 (in Polish).

12. Stanisz A., 2006. Accessible statistics course using STATISTICA PL on examples from medicine, vol 1 basic statistics, StatSoft, Cracow (in Polish).

13. Wałęga A., Plesiński K., Chmielowski K., Satora S., 2010, enhancement possibilities of nitrogen and phosphorus removal from sewage in the treatment plant in Lopuszna, Infrastructure and Ecology of Rural Areas, no. 1, 111-123 (in Polish).

14.Żaba T., Królikowski A., Królikowska J., 2011. Failure frequency for a small water treatment plant, Journal of Ecological Engineering, no. 24, 215-225 (in Polish). 